\title{
DESCONSIDERAÇÃO DA PERSONALIDADE JURÍDICA: ASPECTOS GERAIS E USO INCIDENTAL
}

\author{
JACQUELINE ANDRESSA LUI \\ Professora Mestre Daniela Pozza Batista**
}

RESUMO

O objetivo do presente trabalho é abordar os diferentes aspectos da desconsideração da personalidade jurídica, enfatizando seus requisitos, modalidades, mudanças decorrentes da reforma do CPC em 2015, assim como a possibilidade de sua aplicação da prática. O estudo foi baseado em doutrinas sobre o assunto, legislação específica e a aplicação prática em casos reais. O principal intuito do trabalho é apresentar a possibilidade e características específicas de um instituto, qual seja, a desconsideração da personalidade jurídica que permite atingir o patrimônio dos sócios ou da empresa, sendo verificado o desvio de finalidade ou da confusão patrimonial. Deste modo, tendo conhecimento sobre a tese, será possível prever quando essa poderá ser aplicada ou não, podendo assim encontrar meios para quitar eventual saldo devedor.

Palavras-chave: Incidente da desconsideração da personalidade jurídica. Direito Processual Civil. Código de Processo Civil de 2015.

\section{DISREGARDING LEGAL PERSONALITY: GENERAL ASPECTS AND INCIDENTAL USE}

\section{ABSTRACT}

The objective of the present work is to address the different aspects of the disregard of the legal personality, emphasizing its requirements, modalities, changes resulting from the reform of the CPC in 2015, as well as the possibility of its application of the practice. The study was based on doctrines on the subject, specific legislation and practice in real cases. The main purpose of the work is to present the possibility and specific characteristics of an institute, that is, a disregard of the legal personality that allows to reach the equity of the partners or of the company, being verified the deviation of form or the patrimonial confusion. In this way, taking into account the knowledge, it will be possible to predict when it may be applied or not, thus being able to find ways to settle any outstanding balance

Keywords: Incident of disregard for legal personality. Civil Procedural Law. Code of Civil Procedure 2015.

* Advogada. Graduada em Direito pela Universidade Metodista de São Paulo em 2019. Pós-graduanda em Direito Tributário pelo Instituto Brasileiro de Estudos Tributários -IBET. E-mail: j.lui05@hotmail.com

** Mestre em Direito, Advogada, Professora Universitária e Coordenadora do EAJ - Escritório de Assistência Judiciária 


\section{INTRODUÇÃO}

Em virtude da pandemia causada pelo novo coronavírus (sars-cov 2)a escolha do tema foi delimitada não somente pela habitualidade com o assunto, em decorrência do trabalho, mas também pela sua importância no âmbito jurídico, que, por consequência, atinge o cenário econômico atual, que sofre diversas crises.

Visando restringir os abusos da autonomia patrimonial realizada por pessoas jurídicas por meio das fraudes, estas sempre executadas com o intuito de evadir-se do adimplemento de uma obrigação, que, na maioria das vezes, perdura por anos, é possível a aplicação da tese de desconsideração da personalidade jurídica, tendo assim uma maneira de buscar a satisfação do crédito.

A maioria dos casos em que incidem as fraudes são aqueles em que já foram realizadas todas as pesquisas habituais no processo, restando sempre infrutíferas. Sendo, portanto, cabível, o incidente de desconsideração da personalidade jurídica contra aquele que praticou tal ato ilícito.

Ademais, o tema é de suma importância para o direito, pois possui o intuito de coibir fraudes praticadas pelos sócios que se aproveitam das suas sociedades ou vice-versa. Bem como resguardar direitos de terceiros de boa-fé, que, muitas vezes, com a prática dessas condutas acabam prejudicados.

Deste modo, o texto a seguir está organizado em seções. A primeira delas Aspectos gerais da pessoa jurídica concentra-se em explicar a relevância da pessoa jurídica para o instituto da desconsideração da personalidade jurídica. A seguinte seção A desconsideração da personalidade jurídica descreve os aspectos da tese e a terceira seção Hipóteses de aplicação da desconsideração da personalidade jurídica demonstra a aplicação da tese e quais são os seus efeitos. Por fim, são abordadas as considerações finais sobre o trabalho.

\section{ASPECTOS GERAIS DA PESSOA JURÍDICA}

Primeiramente, antes de abordar o tema principal, é de suma importância explicar sobre a pessoa jurídica, a fim facilitar o entendimento. A pessoa jurídica nada mais é que a união de um grupo de indivíduos que possuem em comum um mesmo objetivo, ou seja, todos se tornam membros de um grupo que tem por fim determinada atividade.

Existem dois tipos de pessoa, a pessoa natural e a pessoa jurídica, o que distingue as duas é a forma como um grupo de indivíduos irá se relacionar frente aos interesses comuns ou sociais. Ambas detêm personalidade, porém a pessoa jurídica se "compõe ora de um conjunto de pessoas, ora de uma destinação patrimonial, com aptidão para adquirir, exercer direitos e contrair obrigações " (PEREIRA, 2017, p.250).

Com isso, a pessoa jurídica é resultante de um fenômeno histórico e social, como assim também entende o autor Carlos Roberto Gonçalves (2017, p.233), em que pessoas jurídicas "consistem num conjunto de pessoas ou de bens, dotados de 
personalidade jurídica própria e constituídos na forma da lei, para a consecução de fins comuns ".

Ressalta-se que a pessoa jurídica sempre será representada por alguns de seus integrantes, com intuito de ser responsabilizada por seus atos em qualquer hipótese. Não obstante, para a concepção desta, é necessária a junção de três requisitos, conforme preceitua Caio Mário da Silva Pereira:

Para a constituição ou nascimento da pessoa jurídica é necessária a conjunção de três requisitos: a vontade humana criadora, a observância das condições legais de sua formação e a liceidade de seus propósitos (PEREIRA, 2017, p.250).

Assevera também Gilberto Gomes Bruschi:

Para possibilitar a existência de pessoa jurídica, são necessários três requisitos: a) a organização de pessoas ou bens; b) a licitude de propósitos ou de finalidades; e c) a capacidade jurídica da entidade (BRUSCHI. 2009. p. 05).

Existindo a pessoa jurídica em decorrência destes requisitos, é possível que ela seja atingida tanto no direito privado quanto no público. Porém, há de se destacar que a aplicação da desconsideração da personalidade jurídica tem mais incidência naquelas de direito privado, em virtude da amplitude que este possui comparado ao público, que é mais restritivo.

Não obstante, existem inúmeros casos em que a pessoa jurídica se utiliza de seu fim de maneira diversa da qual seria habitual, realizando fraudes com intuito de evadir-se de pagamentos. Posto isso, o instituto da desconsideração da personalidade jurídica existe para coibir esse feito, bem como buscar maneiras satisfatórias de cumprimento de uma obrigação, tese que será possível verificar nas próximas seções.

Além disso, os doutrinadores discutem as teorias acerca da natureza da pessoa jurídica sendo a teoria da ficção, da propriedade coletiva, da instituição e a realista. Nesse sentido, é oportuno destacar a teoria que atualmente é aceita na jurisdição moderna, a teoria realista.

A teoria em questão possui três vertentes, sendo, a teoria da realidade objetiva ou orgânica, a teoria da realidade jurídica ou institucionalista e a teoria da realidade técnica.

A teoria da realidade objetiva ou orgânica considera que a pessoa jurídica "é uma realidade sociológica, ser com vida própria, que nasce por imposição das forças sociais" (GONÇALVES, C., 2017, p.235). Portanto, não se abrange nesta teoria a possibilidade de os grupos sociais adquirirem personalidade jurídica.

A teoria da realidade jurídica ou institucionalista sustenta que as pessoas jurídicas são destinadas a um determinado serviço ou ofício e, devido à isso, possuem personalidade jurídica. Processa-se Ocorre que, assim como a orgânica, é falha, pois exclui os grupos de pessoas jurídicas que não possuem o intuito de oferecer um serviço. 
Por fim, a teoria da realidade técnica é a mais aceita pelos doutrinadores, conforme ressalta Caio Mário da Silva Pereira:

O jurista moderno é levado, naturalmente, à aceitação da teoria da realidade técnica, reconhecendo a existência dos entes criados pela vontade humana, os quais operam no mundo jurídico adquirindo direitos, exercendo-os, contraindo obrigações, seja pela declaração de vontade, seja pela imposição da lei (PEREIRA, 2017, p. 259).

Isto é , a pessoa jurídica possui vontade e objetivos próprios, existindo no mundo real; logo um "grupo de pessoas, com objetivos comuns, pode ter personalidade jurídica própria, que não se confunde com a de cada um de seus membros" (GONÇALVES, C., 2017, p.237).

No mais, é a teoria adotada pelo direito brasileiro. Além disso, é possível observar as disposições sobre as pessoas jurídicas dos artigos 40 ao 52 do Código Civil. Deste modo, cabe destacar que a existência legal da pessoa jurídica está explícita no artigo 45, caput:

Começa a existência legal das pessoas jurídicas de direito privado com a inscrição do ato constitutivo no respectivo registro, precedida, quando necessário, da autorização ou aprovação do Poder Executivo, averbando-se no registro todas as alterações por que passar o ato constitutivo. (BRASIL.CC, 2002).

Sendo assim, resta claro que as pessoas jurídicas "têm o poder jurídico limitado aos direitos de ordem patrimonial", (PEREIRA, 2017, p.259), bem como "o gozo dos direitos civis que lhe são necessários à realização dos fins justificativos de sua existência" (PEREIRA, 2017, p. 260).

\section{A DESCONSIDERAÇÃO DA PERSONALIDADE JURÍDICA}

Deve ser observado que antes de aprofundar propriamente o tema da desconsideração da personalidade jurídica, é relevante entender sobre a definição de empresa e posteriormente sobre a formação dos grupos econômicos.

O conceito de empresa é algo em constante evolução, que todos os dias avança tanto no aspecto tecnológico, econômico, produtivo, estrutural, quanto no aspecto societário.

Inexiste uma padronização de concepção de empresa entre os doutrinadores. Entretanto, cabe mencionar o conceito adotado pela autora Suzy Elizabeth Cavalcante Koury:

Segundo a concepção restritiva, o termo empresa deve ser reservado à empresa capitalista, a qual se caracteriza pelo recurso ao trabalho alheio e pela finalidade lucrativa que inspira sua atividade. [...] A concepção extensiva é todo organismo que se propõe essencialmente a produzir para o mercado certos bens ou serviços, sendo independente financeiramente de qualquer outro organismo (KOURY, 2018, p.33). 
Nesse sentido, entende-se que uma empresa possui um centro de produção econômica, que gera serviços, produtos, lucros, levando-se em conta também os riscos destes fatores. Destaca-se, ainda:

Na medida em que a empresa é credora e devedora, assumindo direitos
e obrigações, ela deve ser tida como pessoa jurídica, não sendo correto,
portanto, restringir-se o reconhecimento de sua personalidade ao aspec-
to contábil, o qual constitui, em verdade, mais uma das evidências de
sua personificação (KOURY, 2018, p.35).

Desse modo, a personalidade da empresa se distingue da de seus sócios, empresários, assim, cada qual responde pelos seus atos. Essa acepção tem muita relevância para o aspecto da responsabilidade patrimonial, nos casos de fraude, bem como abuso de poder e desvio de finalidade, podendo esses serem praticados tanto pela empresa, quanto somente pelos seus sócios. Sendo que, nessas hipóteses, será possível desconsiderar a personalidade jurídica de ambos, a fim de satisfazer uma obrigação.

Porém, deve-se ressaltar que a "dissociação entre empresa e empresário se mostra bem nítida somente no âmbito das grandes empresas e grupos econômicos os quais apresentam natureza institucional e não societária" (KOURY, 2018, p. 52).

Sendo assim, a partir da concepção de uma empresa, há uma imensa ratificação produtiva e econômica no meio social, fator este que se não for dosado da maneira correta, acarretará diversos prejuízos. Ressalta-se também a distinção entre o sócio e a empresa, tendo em conta que isto implica no modo de aplicação em uma possível desconsideração da personalidade jurídica.

Diante do exposto, é inegável que atualmente as empresas dominam a economia; não é à toa que estão em constante evolução. Porém, é possível verificar que algumas empresas se aproveitam do seu campo de atuação para realização de fraudes, atos ilícitos, a fim de exonerarem-se do pagamento de dívidas.

Logo, as empresas que estão devendo, criam uma nova empresa, que possui o mesmo ramo de atuação, comando em comum, e, por incrível que pareça, em algumas situações, até o mesmo endereço da empresa devedora, o que se caracteriza como a formação dos grupos econômicos.

Em uma primeira análise, não é clara a formação de um grupo econômico, isto porque para tanto são necessários a existência de direção com comando comum, bem como o mesmo objeto social.

A fim de enfatizar a formação de um grupo econômico, segue jurisprudência do Tribunal Superior do Trabalho:

Agravo de instrumento, Recurso de Revista. Execução. GRUPO ECONÔMICO. DESCONSIDERAÇÃO DA PERSONALIDADE JURÍDICA DA EXECUTADA;Conforme expressamente consignado do acórdão regional, a hipótese não é de desconsideração da personalidade jurídica com a inclusão de sócios no polo passivo da lide, tal como previsto nos artigos 133 e seguintes do CPC, mas sim, de inclusão de empresa perten- 
cente ao mesmo grupo econômico que a executada. Acrescente-se que, somente após o reexame das provas dos autos, procedimento vedado pela Súmula ${ }^{\circ} 126$ do TST, seria possível afastar a premissa consignada pelo acórdão regional de que ficou caracterizado o grupo econômico, não apenas em razão da existência de sócio em comum, mas também porque demonstrada a relação de mútua colaboração e coordenação estabelecida entre as empresas executadas. Agravo de instrumento conhecido e não provido. (TST- AIRR: 103506620155030146, Relator: Dora Maria da Costa, Data de Julgamento: 04/04/2018. $8^{\circ}$ Turma, Data de Publicação: DJET 06/04/2018) (Grifo Nosso).

Destaca-se, porém, que a existência de direção com comando comum não precisa ser única, ou seja, pode figurar no polo de empresa, o sócio/empresa devedora e algum outro, assim como basta a evidência de colaboração recíproca entre as empresas.

É possível notar que em um grupo econômico ocorre a confusão patrimonial entre as empresas, isto porque, enquanto uma empresa está devendo, as outras estão faturando, sendo, portanto, plenamente cabível atingir o patrimônio destas outras empresas para satisfazer a obrigação adquirida pela empresa devedora.

Desse modo, em virtude da presença de abuso de personalidade, é possível o reconhecimento de formação de um grupo econômico com consequente aplicação do incidente de desconsideração da personalidade jurídica.

Feitas essas explanações, é possível entender sobre o tema da desconsideração da personalidade jurídica que consiste em um meio pelo qual é possível atingir o patrimônio dos sócios, bem como da empresa.

A origem da desconsideração da personalidade jurídica se deu "no âmbito common Law, principalmente no Direito Norte-Americano, que se desenvolveu, inicialmente na jurisprudência" (KOURY, 2018, p. 65). A primeira aplicação da tese ocor-



O comerciante Aaron Salomon havia constituído uma Company, em conjunto com outros seis componentes de sua família, e cedido o seu fundo de comércio à sociedade assim formada, recebendo 20.000 ações representativas de sua contribuição ao capital, enquanto para cada um dos outros membros foi distribuída uma ação apenas; para a integralização do valor do aporte efetuado, Salomon recebeu ainda obrigações garantidas de dez mil libras esterlinas. A companhia logo em seguida começou a atrasar pagamentos, e um ano após, entrando em liquidação, verificou-se que seus bens eram insuficientes para satisfazer as obrigações garantidas, sem que nada sobrasse para os credores quirografários. O liquidante, no interesse desses últimos credores sem garantia, sustentou que a atividade da company era ainda a atividade pessoal de Salomon para limitar a própria responsabilidade; em consequência Aaron Salomon devia ser condenado ao pagamento dos débitos da company após a satisfação dos demais credores quirografários (BRUSCHI, 2009, p. 14). 
Deve ser observado que o comerciante aproveitou de sua personalidade jurídica para fraudar os credores, tendo em vista que sua empresa se encontrava em estado de insolvência.

Dessa forma, passou-se a realizar uma busca além da pessoa jurídica, isto é, as características individuais dos sócios passaram a ser consideradas, a fim de diminuir a incidência de fraudes, estas realizadas por meio de abuso de poder, desvio de finalidade, bem como pela confusão patrimonial. Neste sentido cabe mencionar o autor Gilberto Gomes Bruschi:

A desconsideração da personalidade jurídica teve origem com a clara finalidade de garantir que as sociedades comerciais não fossem utilizadas por seus sócios de maneira indevida, praticando atos ilícitos, com abuso de direito e se ocultando sobre o manto protetor da personalidade jurídica (BRUSCHI, 2009, p.13).

Logo, a desconsideração da personalidade jurídica não visa acabar com a autonomia da pessoa jurídica, mas torná-la eficaz em face dos membros que a estabelecem. Posto isto, cabe salientar:

A disregard é o instrumento hábil que possibilita ao credor o direito de livrar-se da fraude e do abuso praticado, obscuramente, por aquele que gere a pessoa jurídica, mantendo-a, entretanto, íntegra, o que também ocorre com sua autonomia patrimonial. (BRUSCHI, 2009, p.28).

Outrossim, a aplicação da tese de desconsideração da personalidade jurídica foi ganhando repercussão, bem como fundamentação legal com o passar do tempo, considerando que o uso dessa começou antes mesmo de existir uma previsão legal, na qual se aplica subsidiariamente o artigo 135 do Código Tributário Nacional.

Sendo assim, ficou ressaltada a importância de sempre se valer da personalidade jurídica com o intuito de sanar, na maioria das vezes, inadimplementos causados pelo abuso de poder, desvio de finalidade e confusão patrimonial, requisitos estes que, posteriormente, foram inseridos ao artigo 50 do Código Civil, o qual preceitua:

Art. 50. Em caso de abuso da personalidade jurídica, caracterizado pelo
desvio de finalidade, ou pela confusão patrimonial, pode o juiz decidir,
a requerimento da parte, ou do Ministério Público quando lhe couber
intervir no processo, que os efeitos de certas e determinadas relações de
obrigações sejam estendidos aos bens particulares dos administradores
ou sócios da pessoa jurídica (BRASIL.CC, 2002).

Houve uma limitação quanto à desconsideração da personalidade jurídica aos casos de confusão patrimonial e desvio de finalidade, ficando estes limitados ao requerimento da parte ou ainda do Ministério Público, quando este pretender intervir no processo. 
Atualmente, existe previsão legal da desconsideração da personalidade jurídica no artigo 50 do Código Civil, como já mencionado, tal como seu procedimento no artigo 133 do Código de Processo Civil, que é realizado por meio de incidente.

Para mais, é importante evidenciar que, antes da reforma do Código de Processo Civil em 2015, a desconsideração da personalidade jurídica poderia ser requerida na ação principal por meio de mera petição simples. Contudo, após a reforma, conforme citado acima, a desconsideração da personalidade jurídica passou a ser instituída através do incidente que corre em apartado dos autos principais.

A partir da distribuição de um incidente, os andamentos processuais do processo principal serão suspensos, enquanto aguarda-se alguma decisão acerca da desconsideração, deferindo ou indeferindo a tese.

O processo principal só retomará seus andamentos quando se resolver o mérito do incidente. Sendo este positivo, será requerida a inclusão de mais um sócio ou empresa no polo da ação principal.

No Brasil, existem duas teorias acerca da desconsideração da personalidade jurídica, a teoria menor e a maior. As diferenças entre elas são os requisitos necessários para aplicação da tese. Neste sentido, cabe mencionar os ensinamentos de Carlos Roberto Gonçalves:

A doutrina e jurisprudência reconhecem a existência, no direito brasileiro, de duas teorias da desconsideração: a) a teoria maior, que prestigia a contribuição doutrinária e em que a comprovação da fraude e do abuso por parte dos sócios constitui requisito para que o juiz possa ignorar a autonomia patrimonial das pessoas jurídicas; e b) a teoria menor, que considera o simples prejuízo do credor motivo suficiente para a desconsideração (GONÇALVES, C., 2017, p.274).

O Código Civil adota a teoria maior, conforme determina o artigo 50:

Art. 50. Em caso de abuso da personalidade jurídica, caracterizado pelo
desvio de finalidade, ou pela confusão patrimonial, pode o juiz decidir,
a requerimento da parte, ou do Ministério Público quando lhe couber
intervir no processo, que os efeitos de certas e determinadas relações de
obrigações sejam estendidos aos bens particulares dos administradores
ou sócios da pessoa jurídica (BRASIL.CC, 2002).

Posto isso, nota-se que a teoria maior exige para a desconsideração a presença de dois requisitos: que os bens das pessoas jurídicas sejam insuficientes para a satisfação da dívida e que seja comprovada a fraude ou abuso de direito, estes caracterizados pelo desvio de finalidade ou pela confusão patrimonial.

Ressalta-se que a fraude é materializada pelo uso indevido da pessoa jurídica, consequentemente, ocorre o desvio de finalidade, em que a empresa deixa de cumprir com suas reais atribuições. Ou, ainda, a confusão patrimonial, que se configura quando: 
Configura-se a confusão patrimonial quando a sociedade paga dívidas do sócio, ou este recebe créditos dela, ou o inverso, não havendo suficiente distinção, no plano patrimonial, entre pessoas. Igualmente constitui confusão, a ensejar a desconsideração da personalidade jurídica da sociedade, a existência de bens do sócio registrados em nome da sociedade, e vice-versa (GONÇALVES, C., 2017, p.276).

No mais, quanto à teoria menor, é possível verificar que para ocorrer a desconsideração, basta que a pessoa jurídica não tenha bens suficientes para o pagamento da dívida, logo, quando houver a iminência de falta de pagamento ao credor ou ainda um empecilho para tal feito, será aplicada esta teoria.

Ademais, existe também uma variação da desconsideração da personalidade jurídica, sendo a desconsideração inversa que consiste em atingir o patrimônio da sociedade, em virtude de dívidas do sócio, evitando assim que os sócios desviem seus bens para a sociedade como uma maneira de evadir-se de dívidas particulares.

Trata-se de uma variação da tese que visa combater a prática de transferência de bens para a pessoa jurídica sobre a qual o devedor detém controle. Desta forma, evita-se o uso indevido do patrimônio particular. Posto isto, na próxima seção será possível verificar como a desconsideração da personalidade jurídica é aplicada.

\section{HIPÓTESES DE APLICAÇÃO DA DESCONSIDERAÇÃO DA PERSONALIDADE JURÍDICA}

Antes de instaurar um incidente de desconsideração da personalidade jurídica, é necessário passar pelos andamentos comuns de um processo, como inicial, citação, contestação, pesquisa de bens, penhora, dentre outros, até estes se esgotarem. Existe, também, a possibilidade de a desconsideração ser requerida na petição inicial, contudo a probabilidade de deferimento é muito baixa.

Nesse sentido, quando os meios acima descritos se se esgotam e a dívida ainda não foi adimplida, inicia-se uma pesquisa extrajudicial, a fim de satisfazer a obrigação. Ou seja, verifica-se a possibilidade de penhora do faturamento da empresa, se os sócios possuem outras empresas em seu nome, evidências de fraudes, probabilidade do uso de teses como sucessão, cisão, fusão e, por fim, a desconsideração da personalidade jurídica.

Na maioria das vezes, os processos perduram por anos, antes de se tomar algumas das providências citadas acima, logo que estas são mais incisivas e acabam sendo deferidas apenas quando já houver sido utilizados os meios comuns.

Conforme já citado, os pressupostos legais da desconsideração da personalidade jurídica estão presentes no artigo 50 do Código Civil, sendo estes, abuso de direito, desvio de finalidade e confusão patrimonial. Logo, para desconsiderar a autonomia patrimonial da pessoa jurídica e estender as obrigações aos sócios, ou vice-versa, é necessário que, por meio do abuso de direito, ocorra o desvio de finalidade ou a confusão patrimonial. Cabe ainda destacar: 
Nota-se, que a decisão que desconsidera a personalidade jurídica da sociedade não desfaz o seu ato constitutivo, não o invalida, nem importa sua dissolução. Trata, apenas e rigorosamente, de suspensão episódica da eficácia desse ato. Quer dizer, a constituição da pessoa jurídica não produz efeitos apenas no caso em julgamento, permanecendo válida e inteiramente eficaz para todos os outros fins. Em suma, a aplicação da teoria da desconsideração não importa dissolução ou anulação da sociedade (GONÇALVES, C., 2017, p.272).

Verifica-se, portanto, que a desconsideração não é uma regra, tampouco tem o propósito de dissolver a sociedade. Sequer se aplica nas hipóteses em que não estão presentes os requisitos, previstos no artigo em destaque.

Deste modo, cabe destacar previamente a definição de cada um dos requisitos. Inicialmente o abuso de direito se concretiza com o desvio de finalidade ou com a confusão patrimonial, portanto, se aplica a desconsideração quando presente o abuso de direito, visto que a teoria que é adotada atualmente é a teoria maior, em que não basta apenas a insolvência da pessoa jurídica ou a falta de bens, é necessário que seja demonstrado o abuso, por meio do desvio de finalidade ou confusão patrimonial. Ademais cabe salientar:

O fato de conter referência a apenas dois casos de aplicação, quais sejam, o desvio de finalidade e a confusão patrimonial, não traz maiores prejuízos, não só porque entendo que não se trata de enumeração numerus clausus, como também porque, como destacado, é o desvio de função ou de finalidade que justifica todas as hipóteses de aplicação da teoria da desconsideração da personalidade jurídica (KOURY, 2018, p.127).

Ademais, desvio de finalidade é o uso indevido da pessoa jurídica, ou seja, o exercício da personalidade jurídica com intuito diverso da sua real finalidade. Essa estratégia é utilizada pelos sócios ou pela própria empresa como uma maneira de evadir-se de suas obrigações.

Por fim, a confusão patrimonial é a mistura entre o patrimônio dos sócios e o da empresa ou vice-versa, prejudicando outras partes sendo que "configura-se a confusão patrimonial quando a sociedade paga dívidas do sócio, ou este recebe créditos dela, ou o inverso, não havendo suficiente distinção, no plano patrimonial, entre pessoas" (GONÇALVES, C., 2017, p.272).

Dessa forma é como se não houvesse distinção entre o que de fato pertence aos sócios e o que pertence à empresa, fazendo com que os patrimônios se confundam e a pessoa jurídica sirva de instrumento para a prática de atos ilícitos. Quando ocorre a confusão patrimonial, os bens dos sócios podem servir para quitar a dívida da empresa.

O pedido da desconsideração da personalidade jurídica deve cumprir os requisitos previstos em lei, sendo admissível em todas as fases do processo de conhecimento, no cumprimento de sentença e na execução, onde será requerido por meio do incidente. A desconsideração também "se aplica aos processos de competência dos Juizados Especiais, regidos pela Lei n.9.099/1995”. (KOURY, 2018, p.134). 
Cabe ao julgador, antes de deferir a desconsideração da personalidade jurídica: Averiguar as atividades empresariais, bem como a forma e atuação das empresas, a fim de que, ainda na fase de conhecimento, possa investigar a utilização da pessoa jurídica com finalidades contrárias àquelas para as quais foi criada pelo ordenamento jurídico. (KOURY, 2018, p.128)

Ou seja, verificar se está ocorrendo algum abuso de direito, para assim aplicar a tese. Destaca-se que a verificação da existência do desvio de finalidade ou confusão patrimonial também se baseia nos princípios da celeridade e economia processual; logo que caracterizado o abuso, já é possível instaurar o incidente, visando o deferimento.

A partir da distribuição de um incidente, os andamentos processuais do processo principal serão suspensos, enquanto aguarda-se alguma decisão acerca da desconsideração, deferindo ou indeferindo a tese.

Assim cabe mencionar Suzy Elizabeth Cavalcante Koury:

O juiz proferirá decisão de admissibilidade do incidente. Se for negativa, o juiz indeferirá liminarmente o incidente, defendendo que só deverá fazê-lo depois de oportunizar àquele que o suscita o mais amplo e efetivo contraditório, de modo a possibilitar-lhe a demonstração do preenchimento dos requisitos para a sua admissibilidade. Admitindo o incidente, o juiz determinará a suspensão do processo e comunicará a sua instauração ao distribuidor, como previsto no $\$ 1^{\circ}$ do art.134 (KOURY, 2018, p.134).

A decisão que concede ou nega o pedido de desconsideração da personalidade jurídica trata-se de uma decisão interlocutória, contra a qual é cabível o agravo de instrumento, previsto no artigo1015, IV do CPC, quando a decisão for de primeiro grau.

Art.1015. Cabe agravo de instrumento contra decisões interlocutórias que versarem sobre:

IV - incidente de desconsideração da personalidade jurídica. (BRASIL. CPC, 2015).

Ademais também é cabível agravo interno ou regimental, se decisão for proferida pelo relator, assim expresso $\mathrm{n}$ o artigo 136:

Art.136. Concluída a instrução, se necessária, o incidente será resolvido por decisão interlocutória.

Parágrafo único. Se a decisão for proferida pelo relator, cabe agravo interno. (BRASIL. CPC, 2015).

Ainda é possível a oposição de embargos de terceiros, quando um terceiro que não faça parte da relação jurídica tiver algum bem seu penhorado de maneira indevida. Por conseguinte, é possível concluir pela possibilidade de interposição de recurso quanto à desconsideração da personalidade jurídica. 


\section{CONSIDERAÇÕES FINAIS}

Ao longo dos estudos foi possível verificar que a tese de desconsideração da personalidade jurídica é essencial para a inibição de condutas fraudulentas, uma vez que retira a proteção da pessoa jurídica, permitindo que ela também seja responsabilizada por suas ações.

Conclui-se que, na sociedade em que vivemos atualmente, ter conhecimento acerca da possibilidade de aplicação do incidente de desconsideração colabora não só com o sucesso do processo, como também do mercado, reduzindo o número de inadimplentes.

Além disso, verifica-se também que, coibindo a prática de fraudes, tanto das sociedades empresárias quanto dos sócios, evita-se o prejuízo de terceiros inocentes, assim como a possibilidade de adimplir uma dívida, que na maioria das vezes já perdura há anos.

Portanto, a Disregard Doctrine é uma solução positiva para coibir os desvios na função da pessoa jurídica, com o propósito de evitar o uso indevido da autonomia patrimonial entre os sócios e a própria sociedade empresária.

\section{REFERENCIAS}

BRASIL. Código Civil. Jair Lot Vieira, Ed. Pro de Bolso, 2017.

BRASIL. Código de Processo Civil, Saraiva, 2016.

BRUSCHI, Gilberto Gomes. Aspectos Processuais da Desconsideração da Personalidade Jurídica, 2 ed. São Paulo: Saraiva, 2009.

COELHO, Fábio Ulhoa. Curso de Direito Comercial. 28 ed. São Paulo: Saraiva, 2016.

GONÇALVES, Carlos Roberto. Direito Civil Brasileiro. Parte Geral, v.1, 15 ed. São Paulo: Saraiva, 2017.

KOURY, Suzy Elizabeth Cavalcante. A Desconsideração da Personalidade Jurídica (Disregard Doctrine) e os grupos de empresas, 4 ed. São Paulo: LTR, 2018.

PEREIRA, Caio Mário da Silva. Instituições de Direito Civil. v. 1. 30 ed. Rio de Janeiro: Forense, 2017. 